\title{
A Method for Assessing the Impact of Secondary and Tertiary Reactions on Sandstone Acidizing Treatments
}

\author{
B. Lecerf' ${ }^{1}$ N. Flamant ${ }^{1}$, M. Ziauddin ${ }^{1}$ and W. Frenier ${ }^{1}$ \\ 1 Schlumberger, 110 Schlumberger Dr. MD\#2, Sugar Land, TX 77478 - United States \\ e-mail: blecerf@slb.com - nflamant@slb.com - ziauddin@slb.com -wfrenier@slb.com
}

\begin{abstract}
Résumé - Méthode pour estimer l'impact des réactions secondaires et tertiaires lors des traitements d'acidification de gisements gréseux - La stimulation par acidification des gisements gréseux peut accroître considérablement le débit de production d'hydrocarbures, et de ce fait, améliorer la rentabilité économique de l'exploitation. Cette technique de stimulation demeure cependant risquée en raison des réactions secondaires entre la roche et les produits formés lors de la principale réaction de dissolution. Les précipités ainsi formés peuvent in fine annuler les effets bénéfiques de la réaction principale de dissolution. Prévoir l'importance de ces réactions lors du traitement est donc primordial pour le succès de la stimulation.
\end{abstract}

Traditionnellement, l'impact du traitement est évalué en injectant de l'acide dans une carotte et en mesurant le changement subséquent de perméabilité. Toutefois, cette expérience capture essentiellement les effets de la réaction principale. En effet, les réactions secondaires ont lieu sur une durée supérieure au temps de résidence de l'acide dans la carotte, et ne peuvent donc pas être prises en compte rigoureusement par ces expériences.

Nous présentons dans cet article une nouvelle méthode pour évaluer, de façon pratique et avec un coût limité, l'impact des réactions de précipitation sur l'efficacité d'un traitement. Cette méthode nécessite une à deux expériences en laboratoire, sur des carottes de petite dimension (10 à $15 \mathrm{~cm}$ de long), pour mesurer la surface spécifique des minéraux présents dans la roche. Ces résultats sont ensuite exploités grâce à un simulateur géochimique. Ce dernier dispose d'une base de données qui rassemble les propriétés cinétiques et thermodynamiques caractérisant les réactions des acides avec les minéraux qui constituent les réservoirs gréseux. Le simulateur permet d'extrapoler rigoureusement à l'échelle du réservoir les résultats obtenus à l'échelle de la carotte, en prenant en compte l'écoulement radial de l'acide, la minéralogie détaillée de la roche et la nature des matériaux qui restreignent l'écoulement aux abords du puits. La nature des précipités, leur quantité et leur localisation dans le réservoir sont alors déterminées. Ces informations sont utilisées pour optimiser la conception des traitements d'acidification. Cette méthodologie a été appliquée avec succès lors de trois traitements.

- Un puits localisé dans le golfe de Thaillande. La température élevée du réservoir, qui favorise la précipitation de silice colloïdale, et la haute teneur en calcaire constituaient les principales difficultés pour la conception du traitement.

- Un puits localisé en mer du Nord, où l'importance de l'hétérogénéité du réservoir était à prendre en compte pour le passage de l'échelle de la carotte à celle du réservoir. L'absence de traitements antérieurs dans ce gisement rendait nécessaire l'utilisation d'une technique fiable pour la mise au point de ce traitement. 
- Un autre puits localisé en mer du Nord, dans le gisement de Galley. Dans ce cas, à la suite d'incidents survenus pendant l'injection du traitement, l'acide est resté en contact avec la formation pendant plusieurs heures. La méthodologie présentée ici a permis d'évaluer l'impact des réactions parasites sur la productivité.

Dans les deux premiers cas, plusieurs compositions d'acide furent évaluées, ainsi que des études de sensibilité réalisées, pour obtenir une meilleure dissolution des éléments limitant la production tout en minimisant la formation de précipités. Les résultats de ces études ont fourni l'information nécessaire à la mise au point des traitements.

Abstract - A Method for Assessing the Impact of Secondary and Tertiary Reactions on Sandstone Acidizing Treatments - Acid stimulation of sandstone reservoirs can lead to substantial production improvements of hydrocarbons and can considerably enhance the economic value of a well. However, this technique is still considered risky because of secondary and tertiary reactions between the spent acid and the rock. Precipitates resulting from these reactions can deposit in the pores of the rock and eventually negate the positive impact of the primary reaction. Being able to assess the extent of the secondary and tertiary reactions under reservoir conditions is therefore critical for the acid treatment success.

Traditional methods to evaluate overall treatment impact consist of injecting acid through a short core and measuring the change in permeability. However, these methods only capture accurately the impact of the primary dissolution reaction. The much slower secondary and tertiary reactions occur over time scales greater than the acid residence time in the core, and therefore cannot be fully taken into account by these experiments.

This paper presents a new and economical technique to assess the extent of those reactions under reservoir conditions. It relies on one or two experiments performed on short cores of 2.5 to $15 \mathrm{~cm}$ to determine surface areas of reservoir minerals. This information is then incorporated in a geochemical simulator. The simulator includes an extensive database of reaction kinetics and thermodynamics properties of various acids and by-products with the minerals commonly encountered in sandstone reservoirs. Radial flow, reservoir heterogeneities, and damage mineralogy are rigorously accounted for and allow one to scale up to reservoir conditions. The type, amount, and location of precipitates can then be determined. This information is used to optimize the stimulation treatment.

This methodology was successfully applied to three treatments.

- The first case study considers a well in the Gulf of Thailand. The high temperature of the formation, which favors precipitation of silica, and the high carbonate content were challenges for the design of the treatment.

- The second case study considers a well in the Norwegian Sea. A high degree of reservoir heterogeneity had to be accounted for in order to scale up the treatment to reservoir conditions. Without prior acidizing experience in this formation, a reliable means of designing the treatment was required.

- The third case study considers a well in the North Sea. The new technique was applied to determine the damage due to secondary and tertiary reactions from an acidizing treatment on a well in the Galley field, after operational issues caused the acid to stay in the formation over a long period of time.

For the first two cases, various fluid formulations were tested and sensitivity analyses were performed to improve damage removal and minimize the formation of precipitates. The results provided accurate guidelines for the design of the treatments.

\section{INTRODUCTION}

Matrix acidizing consists of injecting a stimulation fluid containing a reactive acid in the reservoir formation to increase its permeability. It represents one of the most cost-effective methods to enhance well productivity and improve hydrocarbon recovery [1]. However, when applied to sandstone, this technique is still considered risky because of the precipitates forming when the spent acid comes in contact with the rock. As a result, formation pores may be plugged, causing the permeability to decrease in the critical region around the wellbore, generally over a $0.5-$ to $1-\mathrm{m}$ radius.

Optimizing the mineral dissolution and minimizing the formation of precipitates while the acid is in the critical matrix is therefore the key to treatment design. It is then essential for the stimulation success to know the extent of the reactions between the acid and the formation minerals under reservoir conditions, over a time length equivalent to the residence time of the acid in the critical matrix. 
In presence of hydrofluoric (HF) acid, sandstone minerals react according to the following reactions:

Primary reaction

$$
\mathrm{HF}+\text { mineral } \rightarrow \mathrm{AlF}_{x}+\mathrm{H}_{2} \mathrm{SiF}_{6}
$$

\section{Secondary reaction}

$$
\mathrm{H}_{2} \mathrm{SiF}_{6}+\text { mineral } \rightarrow \mathrm{AlF}_{x}+\mathrm{SiO}_{2} \cdot 2 \mathrm{H}_{2} \mathrm{O}
$$

\section{Tertiary reaction}

$$
\mathrm{AlF}_{x}+\text { mineral } \rightarrow \mathrm{AlF}_{y}+\mathrm{SiO}_{2} \cdot 2 \mathrm{H}_{2} \mathrm{O} \text {, where } x>y
$$

Due to their importance in determining the outcome of matrix stimulation treatments, secondary and tertiary reactions have been extensively described in the literature [2-4]. However, the extent of these reactions under reservoir conditions remains difficult to quantify.

\section{REVIEW OF CURRENT METHODS FOR TESTING ACID COMPATIBILITY WITH THE FORMATION}

\subsection{Traditional Method}

Traditionally, acid response tests on reservoir rock samples are conducted on linear core plugs of up to $15 \mathrm{~cm}$ in length. Several factors make the traditional acid response tests on short reservoir cores inadequate for characterizing secondary and tertiary reactions. First, secondary and tertiary reactions are slower than primary reactions, so that much longer fluid residence times in the core are required to observe these reactions. Second, linear flow along the axis of the cylindrical cores is not representative of radial flow in a reservoir treatment. Third, cores used in these tests may not be representative of the entire treatment interval.

Figure 1 illustrates the limitations of traditional core flow tests. Figure 1a shows that a core plug is only a small sample of the area of interest. For formations in which the mineralogy changes significantly in the pay zone interval, a single core plug will not be representative of the entire treatment interval.

Figure $1 \mathrm{~b}$ shows how a traditional core flow on a short reservoir core can lead to erroneous conclusions. Shown in the figure are permeability profiles in a simulated reservoir treatment after injection of $620 \mathrm{l} / \mathrm{m}$ of formation height of acetic acid preflush followed by $1242 \mathrm{l} / \mathrm{m}$ each of:

- $12 / 3$ mud acid $^{(1)}$

- an organic fluoboric acid ${ }^{(2)}$.

In both cases the reservoir was undamaged prior to treatment. Simulations show that the $12 / 3$ mud acid treatment provides good stimulation near the wellbore by increasing the permeability, but causes damage deeper in the reservoir where the permeability has decreased below its initial value. The organic fluoboric acid achieves a lesser stimulation near the wellbore but also causes lesser damage deeper in the reservoir than 12/3 mud acid. To compare the overall efficiency of the two treatments, a convenient parameter is the skin factor introduced by [5]. Skin is a dimensionless factor

1 Mud acid is a mixture of hydrochloric $(\mathrm{HCl})$ and hydrofluoric $(\mathrm{HF})$ acids. The numbers in prefix denote the respective weight percentages of $\mathrm{HCl}$ and $\mathrm{HF}$ in the final mixture.

2 Organic fluoboric acid is a mixture of fluoboric acid $\left(\mathrm{HBF}_{4}\right), \mathrm{HCl}$ and an organic acid.
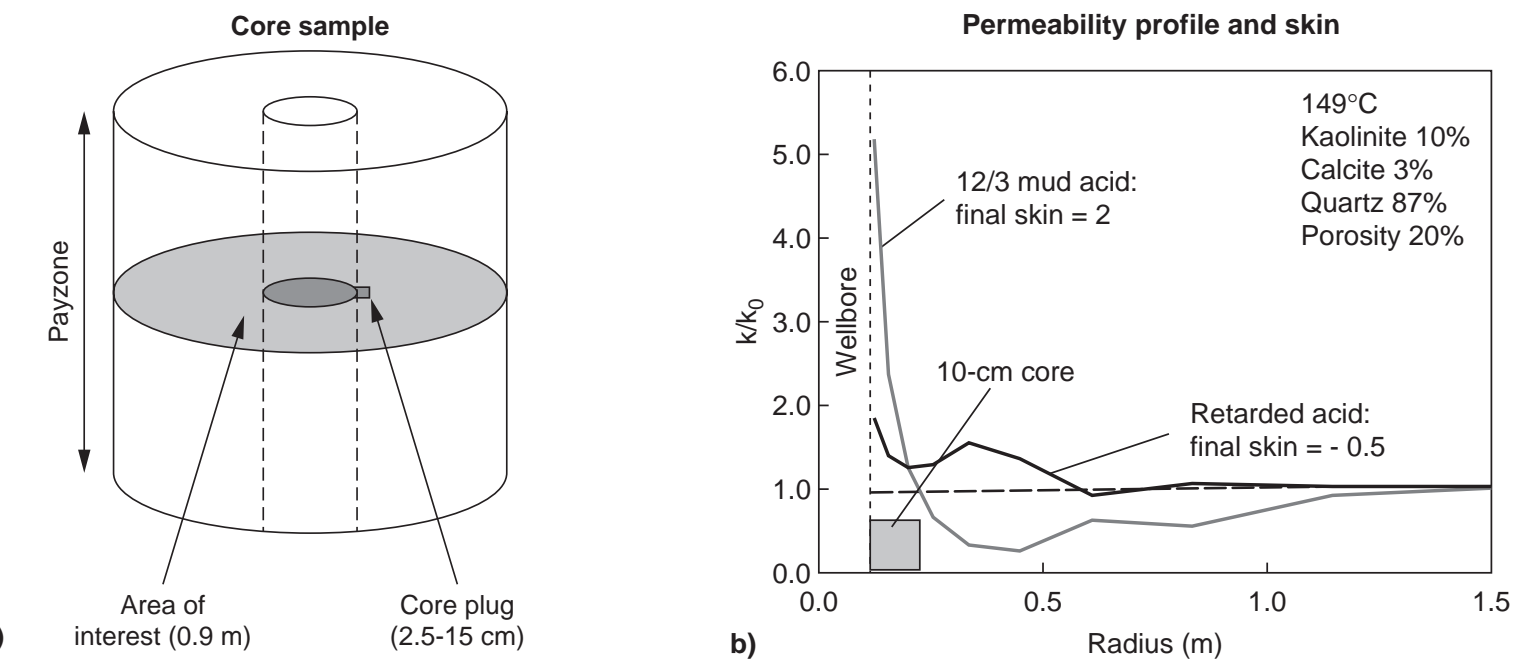

Figure 1

a) core plugs are only a small sample of the area of interest; b) permeability profiles after treatment of an undamaged reservoir with $12 / 3$ mud acid and an organic fluoboric acid. 
calculated to determine the production efficiency of a well by comparing actual conditions with theoretical or ideal conditions. A positive skin value indicates damage impairing well productivity, whereas a negative skin value indicates enhanced productivity. In the example reported in Figure 1, the post-treatment skin for the organic fluoboric acid is -0.5 , compared to a skin of 2 for the 12/3 mud acid. The organic fluoboric acid is, therefore, a better fluid for the stimulation treatment. However, if these two fluids were evaluated with a traditional core flow test, 12/3 mud acid would have been erroneously selected because it provides better stimulation at the length scale of the core (ca. $10 \mathrm{~cm}$ ). Therefore, tests on short cores do not provide by themselves enough information for fluid selection for matrix treatments. For accurate evaluation of a stimulation design, it is necessary to account for the formation damage caused by secondary and tertiary reactions, which are typically not observed in tests on short cores.

\subsection{Other Methods}

To quantify secondary and tertiary reactions, long contact time between the acid and the formation minerals is required to observe precipitation reactions.

To increase the residence time, large cores of up to $0.9 \mathrm{~m}$ in length have been recommended $[6,7]$. The recommended core length of $0.9 \mathrm{~m}$ is also meant to simulate the length scale of the critical matrix. In practice, experimentation with long cores is problematic.

First, long reservoir cores are difficult to obtain, and outcrop or synthetic cores are typically used in their place. Cores from outcrops with mineralogy similar to the reservoir are seldom available and therefore fail to reproduce specific interactions among the various clays that can occur in the reservoir treatment. Clay sedimentation in synthetic cores, which affects the reactive surface area and consequently the reactions rates, is not the same as in the reservoir even for similar bulk mineralogy. Therefore, experiments with outcrop and synthetic cores are not useful in determining specific reactions that may occur under reservoir treatment conditions. Short core tests performed at slow injection rate and experimental designs in which multiple short cores are linked in series to mimic a long core have also been proposed in order to simulate the acid residence time in the critical matrix $[8,9]$. Although these experiments are more representative than experiments with synthetic and outcrop cores, they too suffer from drawbacks, as discussed below.

Second, linear flow along the axis in cylindrical cores is not representative of radial flow in a reservoir treatment. In radial flow, the fluid velocity decreases as the fluid moves away from the wellbore and typically the fluid velocity at about $0.9 \mathrm{~m}$ in the reservoir is only $10 \%$ of the velocity at the sandface. Thus, scaling linear core flows results to radial flow by matching fluid residence times is not straightforward as entrainment and mobilization of fines and precipitates depends strongly on the fluid velocity. Moreover, in typical core flow experiments, these particulates are produced with the effluent but are generally not quantified. In cases where some of these particulates are trapped in the later part of the core, permeability damage may be observed, but it will not be as severe as in a reservoir, where no particulate can exit the formation. Furthermore, core flow tests are typically conducted at constant flow rate and the pressure spikes due to new permeability damage may dislodge particulates that would have otherwise stayed in the core. However, during reservoir treatment, if damage occurs, the resulting increase in injection pressure would divert the flow to other zones and the damage may not be removed. Therefore, simple residence time corrections to correlate linear core flow tests with radial tests are not adequate. An alternative experimentation technique, which accounts for the reduction in fluid velocities in radial flow has been proposed [10]. This technique is more representative of the field treatment than single linear core flow tests. However, the experimental setup requires special instrumentation and equipment, which may not be available in typical laboratories. Moreover, experimental costs can become prohibitive if numerous tests are required.

Third, cores used in the core tests may not be representative of the entire treatment interval. Depending on the degree and scale of reservoir heterogeneity, these differences can be significant. Furthermore, most of the core tests are conducted on undamaged cores because of the difficulties in reproducing the damage in the laboratory. In many cases, the damage consumes a large fraction of the acid. Damage composition is as important as the reservoir mineralogy. Therefore, with core testing alone, it is difficult to assess the interactions between the reaction products from dissolution of damage and reservoir minerals.

In this study, we evaluate an alternative technique for quantifying secondary and tertiary reactions that circumvents many of the problems described above. The alternative technique uses a geochemical simulator in combination with simple experiments with slurry reactors and short reservoir cores, as detailed below.

\section{A NEW TECHNIQUE}

As mentioned earlier, primary, secondary, and tertiary reactions have very different time scales (see Eqs. (1), (2) and (3)). By nature, experimental methods based on core flow tests fail to capture accurately interactions of different time scales, as they show only interactions occurring in the same time scale as the acid residence time in the core. The technique presented in this paper captures short and long time interactions between the rock and the acid with the same accuracy, and over a longer period than typical core flow tests. This is achieved by using slurry reactor tests for the determination of the reaction kinetics. In a slurry reactor, 
samples can be conveniently taken at different contact times, and reaction kinetics are accurately determined for different time scales.

Reaction kinetics determined from slurry reactor tests are archived in the database of a geochemical simulator, which simulates kinetic and equilibrium reactions under various flow geometries. The simulator is used to model linear and radial flow, encountered respectively in core tests and in reservoir conditions. Surface areas of the minerals composing the formation are evaluated from a core flow test, by measuring the element concentrations in the effluent at the exit of a short reservoir core. As primary reaction is very sensitive to the mineral surface areas, a long residence time is no longer required, and only short cores are necessary with this technique. Also, permeability measurements during the core flow test show the impact of the dissolution on the permeability, which is used to calibrate the porosity-permeability relationship in the geochemical model.

Once the reactions and the flow are coupled in the geochemical simulator, mineralogy variations and damage in the formation of interest can be accounted for, yielding results more representative of the interval than from a single short core test. The following section presents each step of the technique in detail.

\subsection{The Geochemical Simulator}

The geochemical simulator plays a crucial role in the treatment design. Details of the simulator including its validation have been presented previously $[2,11]$. Thus, only its main features are summarized in this paper. The geochemical simulator is based on a model, which combines equilibrium and kinetically controlled reactions. This is an improvement over the previous kinetic models, for which the stoichiometry of the reactions must be recomputed at each reaction condition because the equilibrium reactions between various aluminum and silicon fluorides are not considered [12-14]. The simulator uses a computationally efficient Gibbs free energy minimization algorithm to compute the chemical equilibrium between any number of aqueous species and minerals. It is an improvement over the partial equilibrium models previously developed, which tend to be numerically intensive and require a priori separation of the reactions into fast and slow reacting groups and identification of all possible precipitates [15-16].

The geochemical simulator contains an extensive database of reaction kinetics and thermodynamic data of species and minerals. Thermodynamic data for minerals and aqueous species were obtained from various literature compilations [17-19]. Reaction kinetics of individual clays were determined from slurry reactor experiments.

More than 100 slurry reactor tests were conducted to determine the reaction kinetics of common sandstone minerals (clays, feldspars, zeolites) with common fluids over a temperature range of 25 to $177^{\circ} \mathrm{C}$. In these tests the reaction rates were monitored by analyzing the element concentrations in the aqueous phase with an inductively coupled plasma spectrometer (ICP). X-ray diffraction (XRD), a nuclear magnetic resonance spectrometer, and a scanning electron microscope were used to examine the solid phase as needed. In addition, to test the ability of the thermodynamic model to predict the interactions between dissolution products from various minerals, several slurry reactor tests were also conducted with mixtures of minerals.

\subsection{Determination of Kinetics for Reactions of Different Time Scale}

Reaction kinetics of individual clays were determined from slurry reactor experiments. Slurry reactor tests are especially convenient for determining kinetics of reactions of different time scales. First, slurry reactor tests can be run for a long time, which allows characterization of slow precipitation reactions, such as secondary and tertiary reactions. Second, fast reaction kinetics, such as primary dissolution of minerals, are also determined with accuracy by sampling the fluid shortly after it contacts the mineral. Third, in a closed system such as the slurry reactor, the amount of precipitate can be quantified. To determine secondary and tertiary reaction kinetics accurately, the tests were conducted at high clay to acid ratios, over a 5-h period of time. The contact time obtained between the mineral and the acid is thus 20 to 50 times larger than in a typical short core test.

In the new technique, the geochemical simulator mathematically combines the reaction kinetics of individual minerals obtained from slurry reactor tests and predicts the results for a mixture of minerals. A thermodynamic model is used to predict interactions between the dissolution products from various minerals. The main advantage of this approach is that, once the reaction kinetics for a pure mineral with a fluid are determined, they are archived in a database to be reused in all future treatments in which the same mineral and fluid system are encountered.

Figure 2 shows a sample of data from slurry reactor tests that were used in determining the reaction kinetics in the geochemical simulator. Shown in the figure are the evolutions of aluminum $(\mathrm{Al})$ and silicon $(\mathrm{Si})$ concentrations in the aqueous phase during dissolution of kaolinite clay with $9 / 1$ mud acid(3) and fluoboric $\operatorname{acid}^{(4)}$. Symbols in the figure are the measured concentrations, while the solid lines are model predictions. To examine the sensitivity of the slurry reactor test to secondary and tertiary reactions, two simulations were conducted. In the first simulation the primary, secondary, and

\footnotetext{
3 For definition of mud acid, see Note 1.

4 Fluoboric acid is a mixture of $\mathrm{HBF}_{4}$ and $\mathrm{HCl}$.
} 
a) Kaolinite in $9 / 1$ mud acid $65^{\circ} \mathrm{C}$

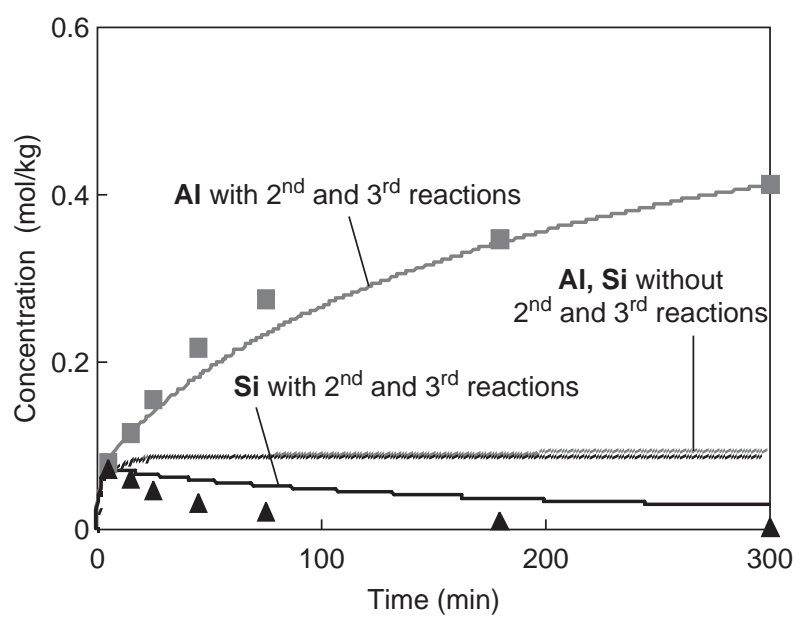

b) Kaolinite in fluoboric acid $65^{\circ} \mathrm{C}$

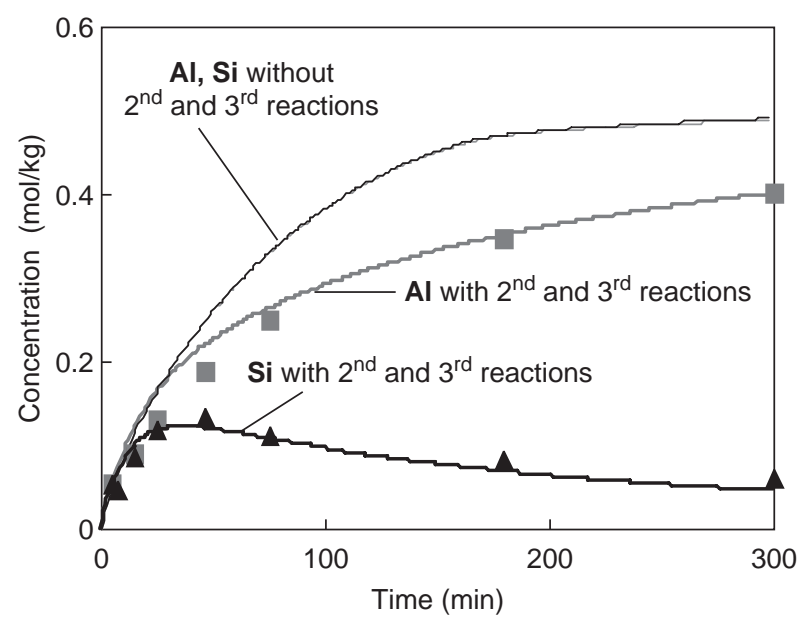

Figure 2

Data from slurry reactor experiments used in determining the dissolution rate of kaolinite in $9 / 1$ mud acid and fluoboric acid. Symbols ( $\mathbf{\square}$ and A) represent the experimental Al, Si element concentrations. The model predictions are shown in solid lines, with and without secondary and tertiary reactions included in the model.

tertiary reactions were included in the model, and in the second simulation only the primary reaction of the clay was included. For the 9/1 mud acid, the predictions with and without secondary and tertiary reactions start deviating significantly after about $5 \mathrm{~min}$ of reaction time, while for the fluoboric acid (a retarded acid) significant deviations are observed after $25 \mathrm{~min}$. These trends are quite easily detected in slurry reactor test. However, in a short core test the typical fluid residence time is less than $5 \mathrm{~min}$ and contribution from secondary and tertiary reactions would be difficult to observe. Therefore, slurry reactor tests are much more sensitive to the kinetics of secondary and tertiary reactions and more precisely determine the kinetics of these reactions than tests on short cores.

\subsection{Determination of Mineral Surface Areas and Porosity-Permeability Relationship for the Formation}

Once the reaction kinetics for individual minerals in the reservoir are obtained, core tests with short reservoir cores are conducted to calculate the surface areas of the minerals in the reservoir and to calibrate the porosity-permeability correlation used in the model. These tests are required because the mineral surface areas in the core are generally different from those in slurry reactors. Typically, one to two core experiments are sufficient for this purpose. However, if a reservoir core is not available, average values of these parameters from formations with similar geology and mineralogy are used to estimate the treatment outcome.

\subsubsection{Determination of the Mineral Reactive Surface Area}

Prior to the core flow test, the mineralogy of the sample is determined by XRD. Then, the recommended procedure is to measure the element concentrations such as $\mathrm{Al}$ and $\mathrm{Si}$ in the effluent from the core, in addition to measuring the permeability response during the core test. The core flow test is then simulated with the geochemical simulator and the mineral surface areas in the simulator are calibrated to match the measured element concentrations. All other kinetic and thermodynamic parameters are kept constant during this calibration.

The simulator computes a change in core porosity for a given effluent element concentration. This change in porosity and the measured permeability response during the core test are used to calibrate the permeability-porosity correlation in the simulator.

\subsubsection{Determination of the Porosity-Permeability Relationship}

The function used to compute permeability from porosity changes is

$$
\frac{k}{k_{0}}=\prod_{i=1}^{i=N}\left[\frac{\phi_{0}+M_{0, i}-M_{i}}{\phi_{0}}\right]^{\delta_{i}}
$$

In this relation, $k$ and $k_{0}$ represent final and initial permeabilities (mD), and $\phi_{0}$ is the original porosity (\%). $M_{0, i}$ and $M_{i}$ are the initial and final volume fractions of mineral $i\left(\mathrm{~m}^{3} / \mathrm{m}^{3}\right)$. The functional form of the porosity-permeability relationship 
used in the model is similar to the one proposed by Labrid [20]. However, there is one important difference. The parameter $\delta_{i}$ in our model is specific to each mineral and allows the mineral identity to impact the permeability, whereas in the form suggested by Labrid it is independent of mineral identity. In our model the higher the value of $\delta_{i}$ for a mineral, the stronger the impact its dissolution or precipitation will have on the permeability.

More than 50 cores from various formations were tested under a wide range of conditions to validate the geochemical simulator. The range of core lengths used in the test was from 2.5 to $92 \mathrm{~cm}$. The temperature range was from 25 to $177^{\circ} \mathrm{C}$. Traditional fluids such as mud and organic mud acids ${ }^{(5)}$, and nontraditional fluids such as retarded acids and chelating agents were tested. The permeability response during the tests was measured and the effluent from the core was analyzed with an ICP. For long cores (>0.3 m) multiple pressure taps along the cores were used to track the permeability fronts. The data collected show that once the geochemical simulator is calibrated with one core test, the results for other tests on the cores from the same formation but for a different set of input conditions (such as different core lengths, injection rates, fluids, or temperatures) can be predicted accurately. Samples of the core tests used in validation of the geochemical simulator are shown in Figure 3.

Tests shown in Figure 3 illustrate the ability of the simulator to scale with respect to flow rate. The data reported in the figure is from [21]. Shown in the figure are $\mathrm{Al}$ and

5 Organic mud acid is a mixture of formic acid and hydrofluoric acid. The numbers in prefix denote the respective weight percentages of formic acid and hydrofluoric acid in the final mixture.
Si concentrations in the effluent from the core as a function of pore volumes of fluid injected. Symbols in the figure are the measured concentrations, while the solid lines are model predictions. Both cores shown in Figure 3 are from the Kekiktuk formation in Alaska and were acidized with 12/3 mud acid but at different flow rates. The flow rate in the test shown in Figure $3 b$ is approximately three times the flow rate for the test shown in Figure 3a. The same mineral surface areas were used for all simulations shown in the figure. A good match between measured and predicted values is obtained. This ability of the geochemical simulator to scale with respect to flow rate after calibration on a single flow rate is crucial for later predicting results in radial flow, where the fluid velocity constantly decreases as the fluids move away from the wellbore.

\subsubsection{Predictions on Radial Geometry}

Once the simulator is calibrated for the formation of interest, it is run in radial flow mode to predict the results of the reservoir treatment.

Radial flow in the geochemical simulator is accounted for by calculating the reduction in the fluid velocity in grid cells as the fluids move away from the wellbore. A nonuniform grid is used to simulate a radial distance of $3.7 \mathrm{~m}$ in the reservoir. An important aspect of scale-up to radial flow conditions is the prediction of the location and quantity of precipitates from secondary and tertiary reactions in the reservoir. Since the reaction kinetics are obtained from slurry reactor tests, which are much more sensitive to these reactions than core flow tests, an improved prediction is achieved with the new technique. a) Flow test on Kekiktuk core (Alaska)

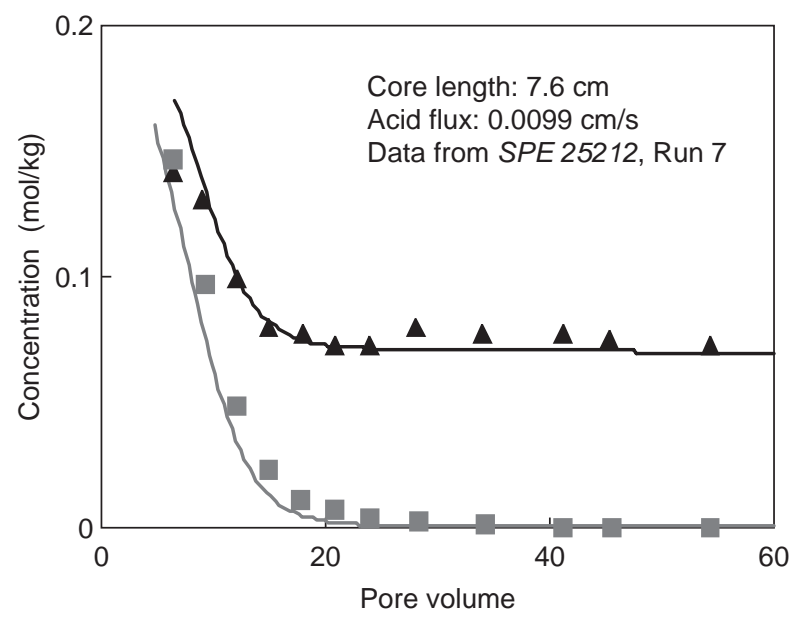

b) Flow test on Kekiktuk core (Alaska)

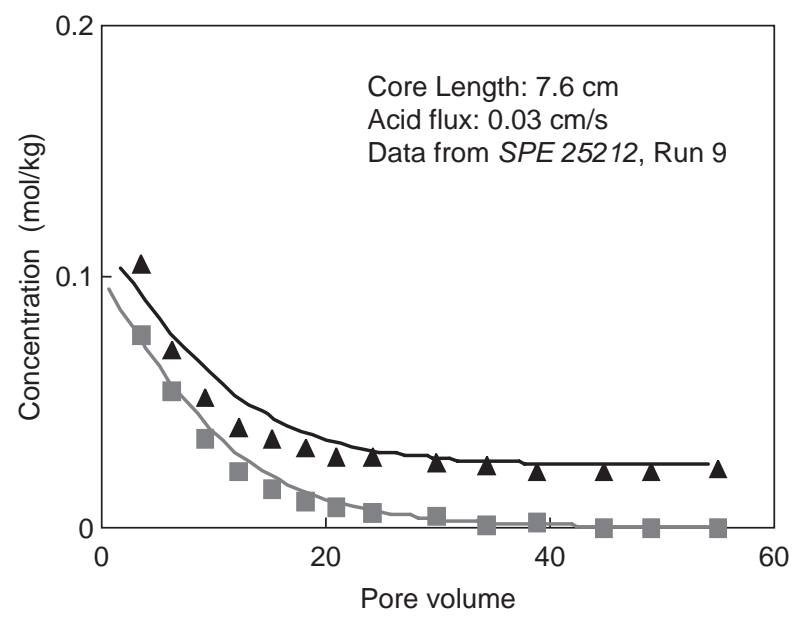

Figure 3

Core tests run at different flow rates, used in the validation of the geochemical model. Symbols $(\boldsymbol{\square}$ and $\mathbf{\Delta})$ represent the experimental $\mathrm{Al}$, Si element concentrations from [21]. The model predictions are shown in solid lines. 
If well logs are available, the effects of heterogeneities in the treatment interval, such as variation in mineralogy and permeability, can be accounted for by running multiple simulations. The extent of the damage can be estimated from the damage skin. Skin is evaluated from production system analysis and from production and drilling logs. This information can be used to define initial mineral profiles for reservoir and damage minerals prior to simulation. If precise information about the damage and reservoir mineralogy variation is not available, at least sensitivity analysis on these variables can be performed. Unlike alternative design techniques, many treatment scenarios can be simulated relatively easily on the computer to optimize the treatment design and examine "what-if" scenarios.

The three case studies that follow have been selected to show how the technique is currently applied to design acid treatments. The technique was particularly suitable for these challenging designs in areas where no previous treatment had been convincingly successful. Additional information about these case studies can be found in separate publications [22-24].

\section{CASE STUDIES}

\subsection{Optimization of the Volumes Pumped to Treat Wells in the Gulf of Thailand}

The Gulf of Thailand shows similar lithology and conditions across its different offshore fields:

- high clay content (>15\%);

- $\mathrm{HCl}$ sensitive clays;

- high temperatures, above $120^{\circ} \mathrm{C}$;

- high carbonate content (ca. 10\%).

These conditions create a challenging environment for sandstone matrix acidizing. High temperature and high clay content favor precipitation reactions. Previous sandstone acidizing treatments in the Gulf using conventional systems such as mud and fluoboric acids have indeed proven to be ineffective in restoring productivity.

\subsubsection{The Gulf of Thailand Fields and Conditions}

Well history and laboratory testing show that the main factors contributing to the formation damage in the Gulf of Thailand are fines migration and overbalanced drilling. Formation samples show that swelling clays such as smectite and migratory clays such as kaolinite and illite are present in large amounts. As production is typically at high drawdown rates, the clays in the formation tend to migrate to the nearwellbore area, where they plug the pore throats and impede hydrocarbon flow. Furthermore, large quantities of drilling fluid lost in the formation as a result of local drilling practices contribute to damage.

Previous treatments in the Gulf showed that it was possible to achieve some stimulation by removing only the carbonates in the formation through the use of chelating agents. However, the benefits of these treatments were short lived because migratory fines from the reservoir quickly filled up the increased porosity created by the carbonate dissolution. Other acidizing treatments based on fluoboric acid $\left(\mathrm{HBF}_{4}\right)$, which aimed at dissolving fines and stabilizing migratory clays, had lead to damage in approximately $35 \%$ of the wells treated in the formation.

\subsubsection{Treatment Design}

As prior matrix acidizing treatments showed limited success in this formation, it was decided to apply the technique based on the use of the geochemical simulator to design the treatments. Table 1 depicts the reservoir and the formation damage parameters used in the geochemical simulations. Note that the formation has a total carbonate content of $9 \%$ and a total aluminosilicate (clay and feldspar) content of $24 \%$. Such high carbonate and aluminosilicate content coupled with the high reservoir temperature make treatment designs particularly challenging. In addition to dissolving the fines, it was also desirable to include some form of clay stabilization to extend the production gains over a longer period of time than with the previous treatments. The chemical options available for dissolving fines and simultaneously stabilizing clay are all fluids containing $\mathrm{HBF}_{4}$. As these fluids are not compatible with carbonates, an appropriate volume of an acid

TABLE 1

Case study 1. Reservoir and formation damage parameters used in geochemical simulation

\begin{tabular}{l|c|c|c|c|c}
\hline \multicolumn{2}{c|}{ Conditions } & \multicolumn{2}{c}{ Mineralogy } & \multicolumn{2}{c}{ Damage } \\
\hline Height $(\mathrm{m})$ & 8.23 & Mineral & Composition (wt\%) & Composition & Insoluble 40.0\% \\
\hline Wellbore diameter $(\mathrm{cm})$ & 20.3 & Quartz & 67 & $95.5 \%$ \\
\hline Porosity $(\%)$ & 21 & Carbonates & 18 & Skin & Feldspar 4.5\% \\
\hline Permeability $(\mathrm{mD})$ & 30 & Clay & 6 & Penetration (m) & 0.9 \\
\hline Temperature $\left({ }^{\circ} \mathrm{C}\right)$ & 169 & Feldspar & & & 0 \\
\hline
\end{tabular}


preflush must be injected to remove the carbonates near the wellbore. This will prevent precipitation of minerals such as fluorite $\left(\mathrm{CaF}_{2}\right)$, sellaite $\left(\mathrm{MgF}_{2}\right)$ or gibbsite $\left(\mathrm{Al}(\mathrm{OH})_{3}\right)$.

The geochemical simulator was used to select an appropriate acid and optimize the fluid volumes for the preflush and clay stabilizing stages.

TABLE 2

Case study 1. Fluid schedules used in the geochemical simulations

\begin{tabular}{c|c|c}
\hline Fluid & Flow rate $(\mathbf{l} / \mathbf{m i n} / \mathbf{m})$ & Volume $(\mathbf{l} / \mathbf{m})$ \\
\hline $\begin{array}{c}10 \% \text { acetic acid or } \\
5 \% \text { formic acid }\end{array}$ & 20.9 & $\begin{array}{c}931,1242,1552, \\
\text { or } 1863\end{array}$ \\
\hline Clay stabilizing acid & 20.9 & 2484 \\
\hline $\mathrm{NH}_{4} \mathrm{Cl} 5 \%$ & 20.9 & 373 \\
\hline
\end{tabular}

\section{Fluid Selection and Fluid Volume Optimization for Preflush}

The objective of the preflush was to remove carbonates near the wellbore without damaging the clays in the reservoir. Table 2 shows the various design options that were considered for the treatment. $\mathrm{HCl}$ based fluids were not considered because of the instability of clays at such high temperature. The skin evolution during preflush with acetic and formic acids is shown in Figure 4. The figure shows that 10\% acetic acid and 5\% formic acid provide similar skin reduction. Figure 5 depicts the carbonate profiles after 931, 1242, 1552, and $1863 \mathrm{l} / \mathrm{m}$ of each acid. Note that in each case, the radius over which carbonates were removed is much smaller than the fluid invasion radius. For example, for 1242 l/m of acetic

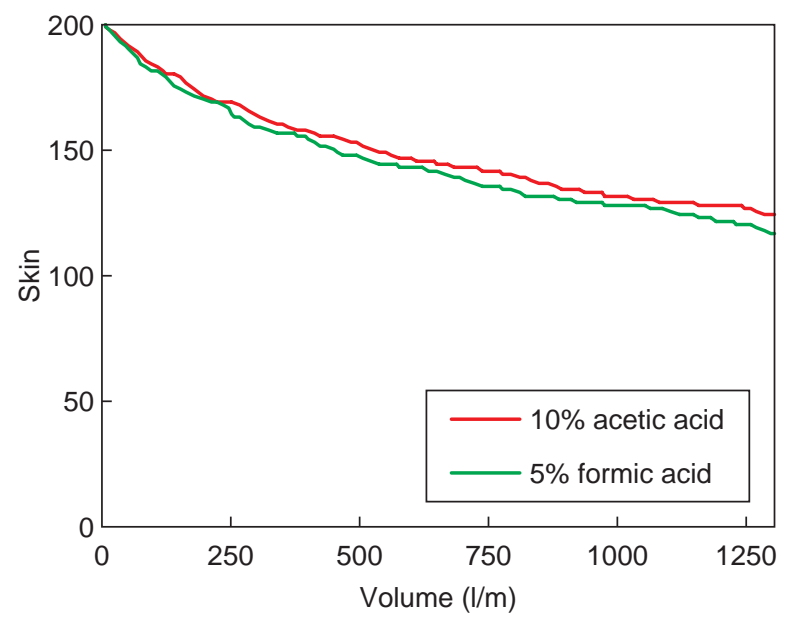

Figure 4

Case study 1. Skin evolution during acetic acid and formic acid preflush. acid, the fluid invades about $1.3 \mathrm{~m}$, while the carbonates are cleaned over only $16.5 \mathrm{~cm}$. The reason for such a short carbonate free radius is the low concentration of acetic acid in the preflush fluid, which limits the dissolving power of the fluid. Also, since acetic acid is weak, all of the acid is not effective in dissolving carbonates. The accurate computation of the carbonate clean radius is essential because it controls the volume of the fluid for clay stabilization that can be safely used and therefore the volume of formation around the wellbore that can be protected from fines migration. The results from the geochemical simulation show that increasing the volume of acetic or formic acid beyond $1242 \mathrm{l} / \mathrm{m}$ provides little incremental benefit and thus this was selected as the volume of preflush to be used in the treatment.

a) After $10 \%$ acetic acid preflush

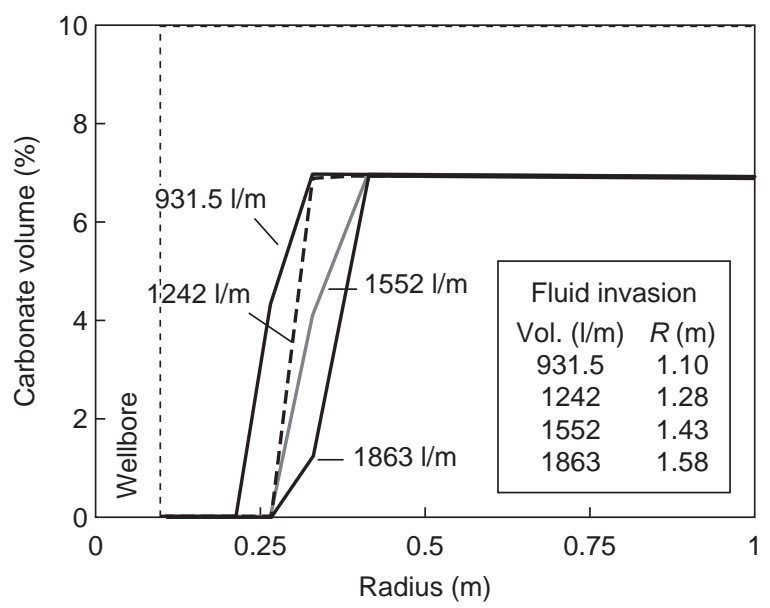

b) After $5 \%$ formic acid preflush

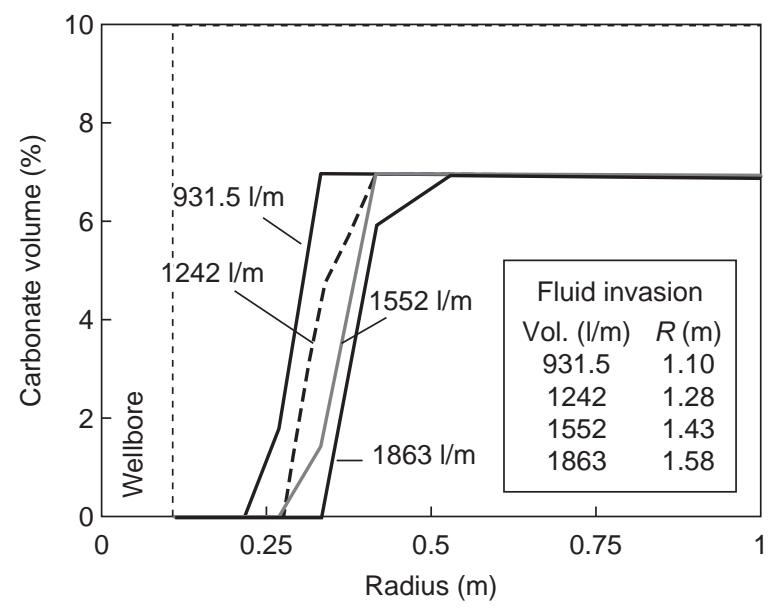

Figure 5

Case study 1. Carbonate profile after acetic and formic acid preflush. 


\section{Optimization for Volume of Clay-Stabilizing Acid}

Figure 6 shows the skin evolution during the clay stabilizing acid stage using $1242 \mathrm{l} / \mathrm{m}$ of acetic or formic acid as preflush. The region near the wellbore where carbonates were removed is similar for both acids (Fig. 5). Therefore, the skin evolution for both acids is also similar. Figure 6 shows that the placement of $1242 \mathrm{l} / \mathrm{m}$ of preflush of either acid allows placement of about $931 \mathrm{l} / \mathrm{m}$ of clay-stabilizing acid before significant negative impact on the skin is observed due to precipitation reactions. However, placing a small amount of stabilizing borosilicate is desired to prevent future fines migration damage around the wellbore. Because of the presence of boron in the clay-stabilizing acid, the borosilicate precipitated from secondary and tertiary reactions tends to fuse the migratory clays to the pore walls [25-27]. Figure 7 shows the volume and the location of borosilicate precipitated in the reservoir for different volumes of the clay-stabilizing acid. The results shown on the figure are for acetic acid preflush. Note that $931 \mathrm{l} / \mathrm{m}$ of clay stabilizing acid allows the protection of $0.3 \mathrm{~m}$ of formation around the wellbore against fines migration. Increasing the protection distance around the wellbore beyond $0.3 \mathrm{~m}$ was not economical in terms of the fluid volume required for the preflush, and therefore $931 \mathrm{l} / \mathrm{m}$ was selected as the optimal volume for the clay stabilizing acid.

\subsubsection{Treatment Execution and Evaluation}

In the Gulf of Thailand, four wells were treated following the design guidelines obtained with the geochemical simulator. Figure 8 shows the hydrocarbons production before and after treatment. All wells showed significant stimulation, which represents a $100 \%$ success rate unmatched by previous acid treatments in the gulf. However, the wells have not yet been on production long enough to evaluate the success of clay stabilization.

\subsection{Treatment Design on a Sensitive Formation in the Heidrun Field}

The Heidrun field presents a high degree of reservoir heterogeneity and high clay content. As no prior matrix acidizing experience existed for the formation, a reliable means of designing the treatment was needed.

\subsubsection{Reservoir Description}

The Heidrun field is located on the Haltenbanken area in the Norwegian Sea, $120 \mathrm{~km}$ south of the Arctic Circle. Recoverable reserves are estimated at $180 \mathrm{M} \mathrm{Sm}^{3 *}$. It was discovered by Conoco in 1985. It has been producing since October 1995 with Statoil as operator.

The main formations in the Heidrun field are the Fangst, Tilje, and Are. The matrix stimulation treatment examined in this case study targeted the Tilje formation at a depth of about $2400 \mathrm{~m}$ and a temperature of 85 to $88^{\circ} \mathrm{C}$. Tilje is heterogeneous with permeability ranging from 10 to $8000 \mathrm{mD}$ over a vertical pay zone thickness of $43 \mathrm{~m}$. Table 3 shows log-derived permeabilities in various zones in the formation. CAT scan images of the core plugs from the Tilje formation showed a number of laminae and clay clasts. Figure 9 shows a picture of a clay clast in a core plug. Because of reservoir heterogeneity, several XRD tests were conducted from cores at various depths. Tables 4 and 5 show XRD results on cores from the

* $\mathrm{Sm}^{3}$ is defined as cubic meter measured under standard pressure and temperature conditions.

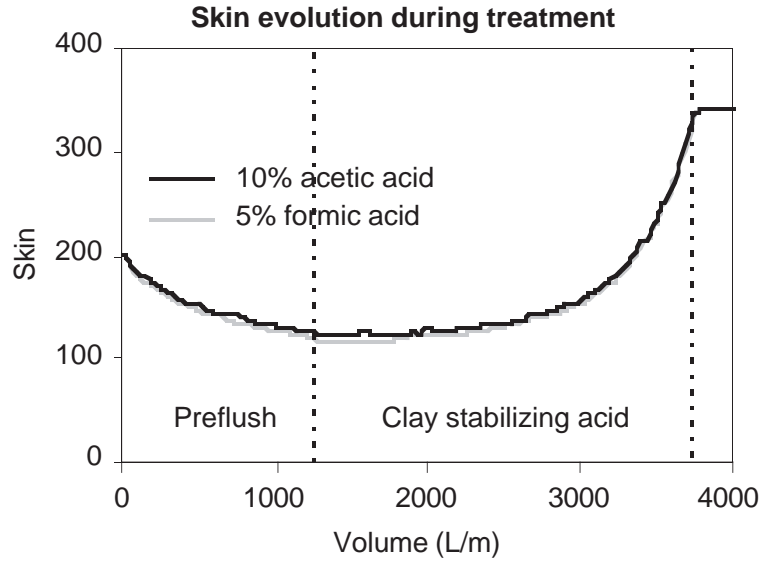

Figure 6

Case study 1. Skin evolution during treatment.

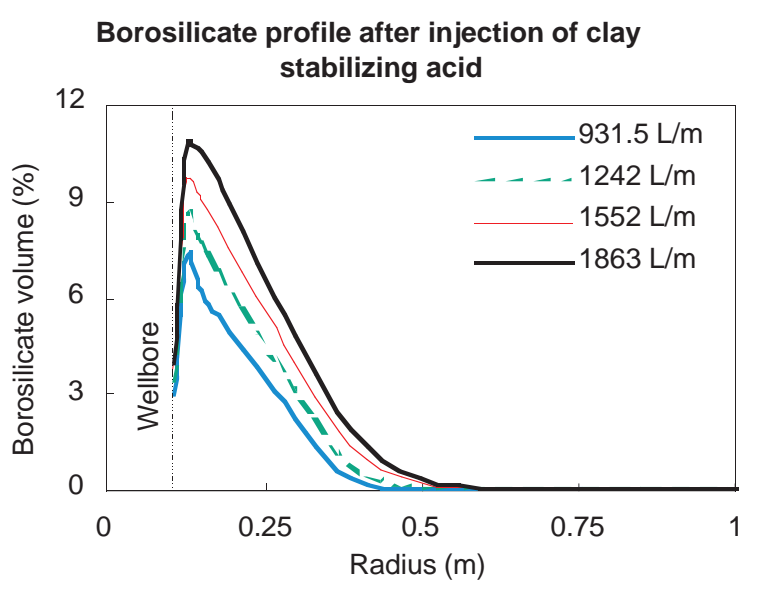

Figure 7

Case study 1. Borosilicate profile after injection of clay stabilizing acid with acetic acid as preflush. 
a) Oil production difference

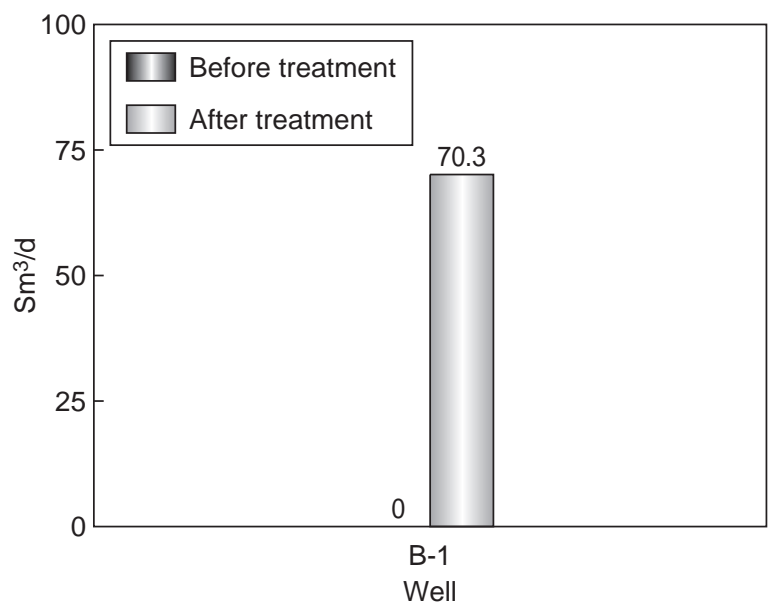

b) Gas production difference

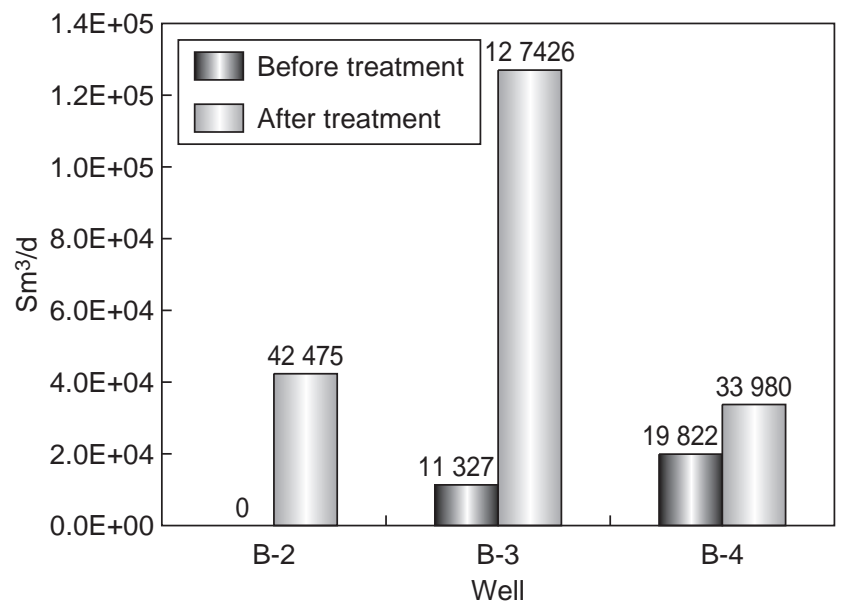

Figure 8

Case study 1. Oil and gas production variance for the 4 wells in the Gulf of Thailand treated with the optimized fluid volumes.

TABLE 3

Case study 2. Formation properties from well log analysis

\begin{tabular}{c|c|c|c|c|c}
\hline Layer & $\begin{array}{l}\text { Measured } \\
\text { depth }(\mathbf{m})\end{array}$ & Length $(\mathbf{m})$ & Permeability (mD) & Porosity $(\boldsymbol{\%})$ & Shale volume (\%) \\
\hline T5 & $4182-4184$ & 2 & 10 & 23 & 29 \\
\hline T4 & $4188-4195$ & 7 & 700 & 26 & 12 \\
\hline T3C & $4196-4217$ & 21 & 500 & 31 & 0 \\
\hline T3B1 & $4220-4225$ & 4.5 & 8000 & 29 & 5 \\
\hline T3B2 & $4225-4240$ & 15 & 1200 & 25 & 12 \\
\hline T3B3 & $4240-4244$ & 3 & 400 & 30 & 2 \\
\hline T3B4 & $4245-4255$ & 10 & 2300 & & 2 \\
\hline
\end{tabular}

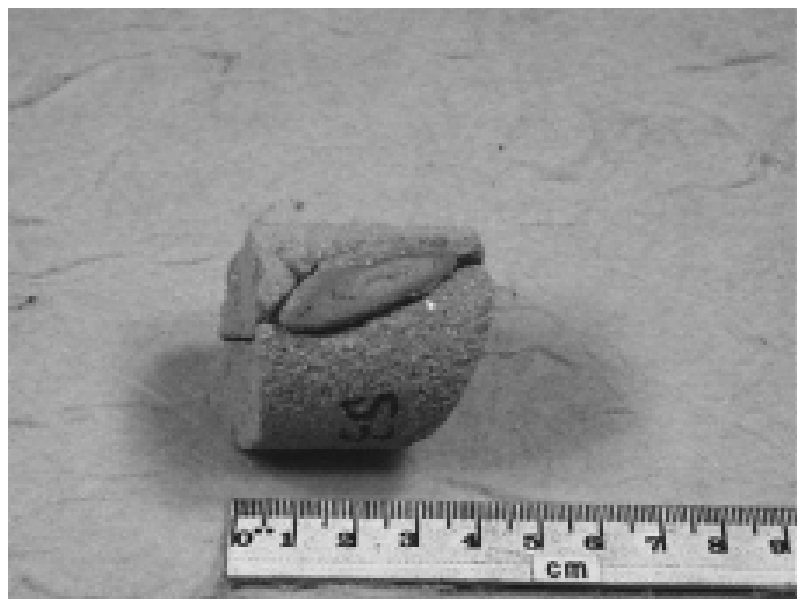

Figure 9

Case study 2. A view of a clay clast in a core plug.
T3B layer in the Tilje formation. The results show that most of the kaolinite and illite clay is in the clay clasts, and the main constituents of the matrix are quartz and feldspar.

The well chosen for this case study was Well A-48. It is an oil producer completed with an openhole gravel pack. The well is deviated, with a deviation angle of 48 degrees across the producing interval. Production from the well started in July 1999, with an initial rate of $3065 \mathrm{Sm}^{3} / \mathrm{d}$ and a gas/oil ratio (GOR) of $59 \mathrm{Sm}^{3} / \mathrm{Sm}^{3}$. Average reservoir permeability and skin from the pressure build up test performed just after the well was put on production were $1220 \mathrm{mD}$ and 1.33 respectively. A gradual decline in production was observed between November 1999 and February 2000. A pressure build-up test in February 2000 showed that the reservoir skin had increased to about 14. A water cut from 5 to $8 \%$ was observed during this period.

Well history analysis and computer simulations suggested that fines migration was the most likely cause of production 
decline from November 1999 onward. The fact that the production decline coincided with the water breakthrough and that the formation had high migratory clay was consistent with this type of damage mechanism. An injection test performed in April 2000 also supported a fines migration damage mechanism, as does previous experience in the field.

TABLE 4

Case study 2. Mineral weight percentages from XRD analysis of whole rock analysis

\begin{tabular}{l|c|c|c|c}
\hline Sample Source & $\begin{array}{c}\text { Quartz } \\
(\boldsymbol{\%})\end{array}$ & $\begin{array}{c}\text { Feldspar } \\
(\boldsymbol{\%})\end{array}$ & $\begin{array}{c}\text { Clay } \\
(\boldsymbol{\%})\end{array}$ & $\begin{array}{c}\text { Siderite } \\
(\boldsymbol{\%})\end{array}$ \\
\hline Matrix sample 1 & 89 & 8 & 3 & 0 \\
\hline Matrix sample 2 & 88 & 10 & 2 & 0 \\
\hline Matrix sample 3 & 86 & 11 & 3 & 0 \\
\hline Clay clast & 63 & 2 & 14 & 22 \\
\hline $\begin{array}{l}\text { Matrix around } \\
\text { clay clast }\end{array}$ & 86 & 11 & 3 & 0 \\
\hline
\end{tabular}

TABLE 5

Case study 2. Mineral weight percentages from XRD analysis of clay fraction (particles less than $2 \mu \mathrm{m}$ )

\begin{tabular}{c|c|c}
\hline Sample Source & Kaolinite (\%) & Illite (\%) \\
\hline Matrix sample 1 & 82 & 18 \\
\hline Matrix sample 2 & 72 & 28 \\
\hline Matrix sample 3 & 93 & 7 \\
\hline
\end{tabular}

\subsubsection{Treatment Design}

Core Flow Test

As described in Section 2.3, core flood tests are needed to calculate the reactive surface areas of the minerals. In the case study examined here, the mineral surface areas were calculated from a single core test with 9/1 mud acid followed by fluoboric acid.

Core plugs for the test were obtained from the same formation but from an adjacent well. The dimensions of the core plug were $3.73 \times 6.4 \mathrm{~cm}$. Fluid treatment schedule and experimental results are presented in Figure 10. No deconsolidation of the cores was noticed.

Experimental data from the core flow test were used to regress mineral surface areas in the geochemical model. Final regression fitted results from the geochemical model are shown in Figure 10a.

Note from Figure $10 \mathrm{~b}$ that the core permeability continued to increase for about three pore volumes during the injection of $8 \% \mathrm{NH}_{4} \mathrm{Cl}$ spacer stage after the $9 / 1$ mud acid stage. A $34 \%$ increase in permeability during this period was attributed to cleanup of mobile fines and precipitates generated by the $9 / 1$ mud acid. In linear core experiments, the cleanup of mobile particulates by the subsequent stage results in an improvement in permeability. However, in a reservoir treatment the damage caused by the $9 / 1$ mud acid would have been moved deeper in the reservoir if a subsequent fluid had been injected. It is difficult to estimate the severity of such damage from linear core flow experiments alone. However, with a combination of core flow experiments and geochemical simulations, one can estimate the mobile fraction of the damage, and consequently the impact of this damage on the final treatment result. In this case, the simulator calibrated with data from the core flow test showed that the impact of this mobile damage on the final treatment result could be significant. In the design, displacing the mobile damage away from the wellbore with a large volume of brine was considered risky, as the reservoir pressure may not have been high enough to allow the well to flow back the large amount of aqueous fluid thus injected. Therefore, in the final treatment design a flowback stage was added at the end of the 9/1 mud acid stage to flow the particulates back to surface and prevent them from causing damage deeper in the reservoir.

\section{Scale-up of Design to Reservoir Conditions}

In the scale-up to reservoir conditions, radial geometry around the wellbore is simulated with the geochemical model. To account for reservoir heterogeneity in the treatment interval, data from various sources were combined. Permeability variation in the treatment interval was estimated by combining log permeability data for each zone (Table 3 ) with core permeability (Fig. 10) and pressure buildup data. In the treatment simulations presented here, a damage penetration distance of $1 \mathrm{~m}$ was used and the reservoir and gravelpack contributions to the damage skin were assumed to be 75 and $25 \%$ respectively.

To estimate the variation in reservoir mineralogy in the treatment interval XRD analyses on cores from various depths were performed (Tables 4 and 5). Bulk mineralogy as well as matrix and clay clast mineralogy were determined. As clay clasts were of comparable dimensions to the core plugs, a CT scan performed on a much larger formation sample was used to estimate the volume fraction of the clasts. This volume fraction was correlated with the clay volume fraction obtained from gamma-ray logs to estimate the mineralogy variation in the entire treatment interval. The damage composition was assumed to have equal portions of feldspars, kaolinite, and illite and was assumed to be the same in the entire treatment interval.

Once the radial flow and reservoir heterogeneity variations are accounted for, the effects of fluid composition, fluid injection sequence, as well as injection rates and volumes of each fluid can be investigated easily. In this case study numerous designs were analyzed to optimize the various design parameters. The final optimized treatment design is shown in Table 6. 

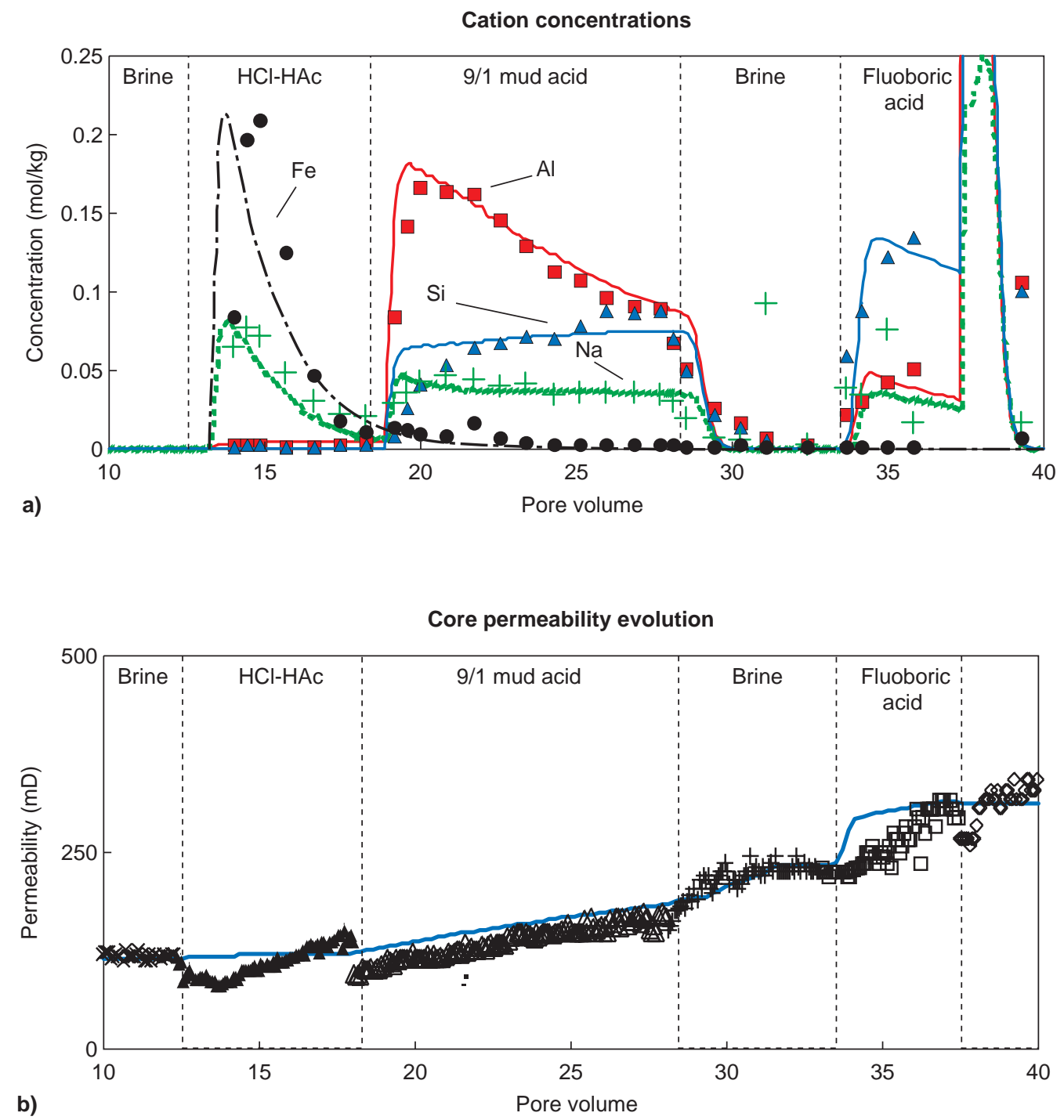

Figure 10

Case study 2. a) cation concentrations and, b) permeability response from core flow tests. Symbols represent experimental measurements, and solid lines represent model predictions.

The design called for flowback of the well after Phase 1 of the design to remove any mobile particulates generated by 9/1 mud acid. The design also called for a 6-h shut-in after the fluoboric acid stage.

Figures 11a through 11f show treatment stimulation results for two representative reservoir zones. Table 3 shows that zone T3B2 has higher permeability and higher initial damage than zone T3C. These zones represent about $60 \%$ of the treatment interval. Figures $11 \mathrm{a}$ and $11 \mathrm{~b}$ show that the mud acid is successful in improving permeability, but the improvement is limited to an area very close to the wellbore. Figures $11 \mathrm{c}$ and $11 \mathrm{~d}$ show that most of the amorphous silica at the end of the mud acid stage is still mobile and can be removed. The resulting increase in permeability is seen in
Figures 11e and 11f. Fluoboric acid is more retarded than mud acid and therefore permeability improvement is realized much deeper in the reservoir (Figs 11a and 11b). Fluoboric acid controls fines migration problems by precipitation of a non-damaging layer of borosilicates [25-27]. Figures 11e and $11 \mathrm{f}$ show that a borosilicate layer has been effectively precipitated near the wellbore in both zones.

\subsubsection{Execution and Post-Treatment Evaluation}

Although design flow rates could not be maintained during execution because of operational difficulties, computer simulations showed that fluid placement was similar to the designed placement [22]. 

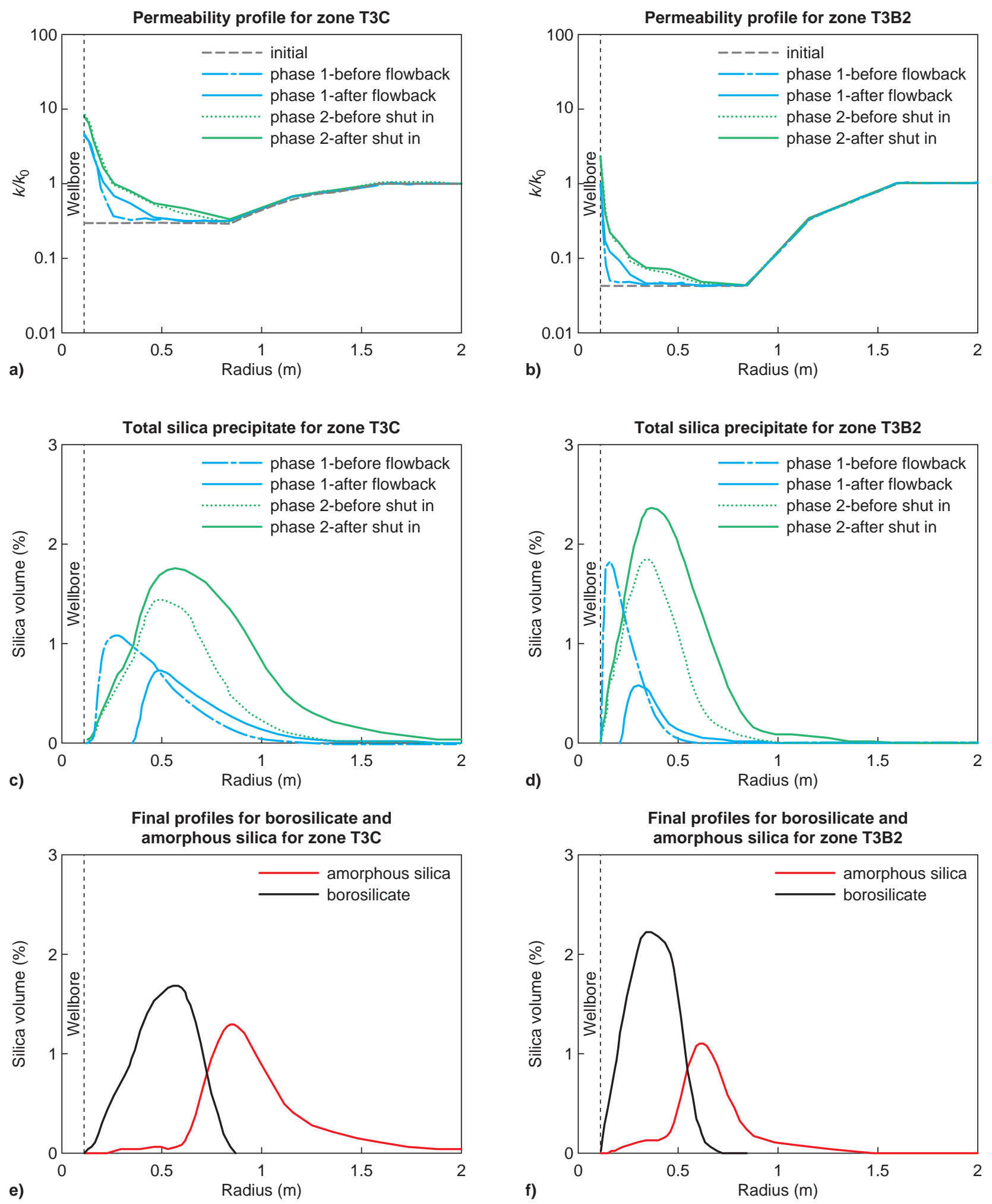

Figure 11

Case study 2. Treatment simulation results for zones T3C and T3B2. 
TABLE 6

Case study 2. Final treatment design schedule

\begin{tabular}{|c|c|c|}
\hline & $\begin{array}{c}\text { Volume } \\
\left(\mathbf{m}^{3}\right)\end{array}$ & $\begin{array}{c}\text { Rate } \\
(\mathrm{l} / \mathrm{min})\end{array}$ \\
\hline \multicolumn{3}{|l|}{ Treatment phase 1} \\
\hline Reservoir gas & 200 & 1200 \\
\hline $\mathrm{NH}_{4} \mathrm{Cl} 8 \%$ & 5 & 1200 \\
\hline $\mathrm{HCl}$-acetic acid $5 / 5$ & 15 & 1200 \\
\hline Mud acid + acetic acid 9/1/5 & 30 & 1200 \\
\hline $\mathrm{HCl}$-acetic acid $5 / 5$ & 5 & 1200 \\
\hline $\mathrm{NH}_{4} \mathrm{Cl} 8 \%$ & 5 & 1200 \\
\hline Diesel oil & 12 & 1200 \\
\hline
\end{tabular}

\begin{tabular}{l|c|c}
\hline \multicolumn{3}{c}{ Flowback stage } \\
\hline Treatment phase 2 & 200 & 1200 \\
\hline Reservoir gas & 5 & 1200 \\
$\mathrm{NH}_{4} \mathrm{Cl}$ 8\% & 14.4 & 1200 \\
$\mathrm{HCl}$-acetic 5/5 & 34.2 & 1200 \\
Fluoboric acid & Well shut in 6 h \\
\hline \multicolumn{3}{c}{ Flowback stage } \\
\hline
\end{tabular}

TABLE 7

Case study 3. Reservoir and well properties

\begin{tabular}{l|c}
\hline \multicolumn{2}{c}{ Reservoir properties } \\
\hline Porosity $(\%)$ & $28-31$ \\
Permeability $(\mathrm{mD})$ & $40-100$ \\
Residual water saturation $(\%)$ & 25 \\
Reservoir pressure $($ atm $)$ & 181.4 \\
Reservoir temperature $\left({ }^{\circ} \mathrm{C}\right)$ & 72 \\
\hline \multicolumn{2}{c}{ Well properties } \\
\hline \multicolumn{2}{c}{ API gravity } \\
GOR $\left(\mathrm{Sm}^{3} / \mathrm{Sm}^{3}\right)$ & $49.1^{\circ}$ \\
Reserves for G5 $\left(\mathrm{Sm}^{3}\right)$ & 183.8 \\
\hline
\end{tabular}

TABLE 8

Case study 3. Mineralogy from XRD

\begin{tabular}{l|c}
\hline \multicolumn{2}{c}{ Whole rock analysis (\%) } \\
\hline Na-feldspar & 6 \\
K-feldspar & 10 \\
Quartz & 77 \\
Clay & 4 \\
Calcite & 3 \\
\hline \multicolumn{2}{c}{ Clay analysis } \\
\hline Mixed-layer illite-smectite & 97 \\
Chlorite & 3 \\
\hline
\end{tabular}

Before the acid treatment the well productivity index (PI) was $20 \mathrm{Sm}^{3} / \mathrm{d} / \mathrm{bar}$, while immediately after the treatment it was $55 \mathrm{Sm}^{3} / \mathrm{d} / \mathrm{bar}$. The average well PI during the 7-month period after the treatment was $42 \mathrm{Sm}^{3} / \mathrm{d} / \mathrm{bar}$. This change shows that the acid treatment was successful in removing the damage and in controlling the fines migration problem.

\subsection{Estimation of Damage Caused by Secondary and Tertiary Reactions in the Galley Field}

The case study presented here documents the use of the new technique to estimate the damage resulting from secondary and tertiary reactions on a well in the North Sea.

\subsubsection{Reservoir Description}

The Galley Field is located wholly within UKCS Block $15 / 23 \mathrm{a}$, approximately $145 \mathrm{~km}$ east-northeast of Peterhead on the Scotland mainland. The acreage is held under license with Texaco North Sea UK Company (67.416\%) as license holder, and partners are Summit UK Oil Limited (17.416\%) and ENI UK Limited (15.168\%).

The Galley Field commenced production on 25 March 1998, and currently produces from three oil accumulations; two Upper Jurassic Galley sandstone member reservoirs and one Late Paleocene Cromarty sandstone member reservoir. The Paleocene reservoir consists of two main areas comprising Paleocene Forties turbidite stacked channel and overbank reservoirs. Reservoir properties are depicted in Table 7. The subject well for this study, G5, is situated in the Forties Channel. The Cromarty channel is a narrow, sinuous channel of fine to very fine-grained, poorly consolidated sandstone that is flanked by laterally extensive overbank deposits. The pay zone height in the channel is about $14.6 \mathrm{~m}$ and the temperature is about $72^{\circ} \mathrm{C}$.

Well G5 is an oil producer, oriented horizontally with a 198-m long openhole section. Initially the well produced without water. However, in March 2002, the water cut started increasing steadily. It reached a level of $8 \%$ in May and then suddenly jumped to $20 \%$. Oil production declined steadily from the initial production rate of $1113 \mathrm{Sm}^{3} / \mathrm{d}$. Even before the onset of any water in March, the oil had declined by $50 \%$ in just 5 months of production and then by $72 \%$ when the water cut jumped to $20 \%$. The oil production had dropped to just $31.8 \mathrm{Sm}^{3} / \mathrm{d}$ before the stimulation treatment was performed.

XRD data obtained from a core sample from the Cromarty Channel are shown in Table 8 . The analysis shows about $20 \%$ aluminosilicates and about $3 \%$ carbonates. Several observations indicated migration of fines was the dominant damage mechanism. First, XRD analysis showed the presence of migratory clays together with silt and mobile quartzitic material. Second, a pump-in test with diesel identified fines migration problems. Third, the production decline correlated with an increase in water production. Water production can destabilize fines and cause them to migrate. 
Furthermore, the unconsolidated nature of the formation and prior experience in the area supported the hypothesis of a fines migration damage mechanism.

A review of the scaling potential of the well indicated that both calcium carbonate $\left(\mathrm{CaCO}_{3}\right)$ and barium sulfate $\left(\mathrm{BaSO}_{4}\right)$ scales were likely. The volume of $\mathrm{BaSO}_{4}$ scale was expected to be small, whereas the volume of $\mathrm{CaCO}_{3}$ scale could potentially be large because of the large pressure drop near the wellbore.

Drilling-induced damage was also suspected. Initially this damage can go unnoticed in a horizontal well. However, it leads to localized production areas, which over time can cause early water breakthrough and accelerate fines migration.

Finally, the well could also have been damaged significantly during the gravel-packing process. Only a quarter of the wellbore length was packed with gravel because of operational issues.

\subsubsection{Treatment Design}

The objective of the treatment design was to remove damage caused by:

- migration of clays, silts, and small quartzitic particles;

- inorganic scale;

- drilling.

A chelating agent was selected to remove $\mathrm{CaCO}_{3}$ scale as well. Acetic acid was selected to provide additional removal of $\mathrm{CaCO}_{3}$ scale as well as to serve as a preflush for the mud acid to remove carbonates in the matrix. A 9/1 organic mud acid (OMA) was selected to remove fines migration and drilling-induced damage. A mud acid formulated with $\mathrm{HCl}$ was not selected because prior core flow tests with these acids had resulted in core deconsolidation. Although the use of a fines stabilization agent, such as fluoboric acid, was thought to be beneficial for the treatment, the stabilization agent was not registered in the region and it could not be used. A final stage with brine postflush was planned at the end of the treatment to transport precipitated material beyond the critical matrix. A coiled tubing with a jetting tool was selected as the preferred method of placing the fluids.

In the first phase of the treatment, the chelating agent was to be jetted along the entire wellbore. This was to be followed by the second phase of the treatment, in which the main oil-bearing zones were to be treated for fines migration and residual drilling damage. The above sequence of preflush, main stage, and postflush was to be repeated for all oilbearing zones. The steps taken to estimate the damage caused by secondary and tertiary reactions induced by the G5 stimulation treatment are as follows.

\section{Core Flow Test}

A $3.73 \times 6 \mathrm{~cm}$ core plug from the Cromarty formation was used for the flow test. The temperature was set at $72^{\circ} \mathrm{C}$, and the fluid sequence was injected. Element concentrations were measured in the effluent of the core, and permeability variations were recorded.

Final regression-fitted results from the geochemical model and comparisons with the measured values are shown in Figure 12. Symbols in the figure indicate measured concentrations, and the solid lines represent the results from the geochemical simulations. No deconsolidation of the core was observed during the test. The figures show that the treatment fluids provide an increase in permeability at least at the core length scale.

\section{Scale-up to Reservoir Conditions}

The reservoir treatment was simulated in the geochemical simulator to see if it would provide a net increase in
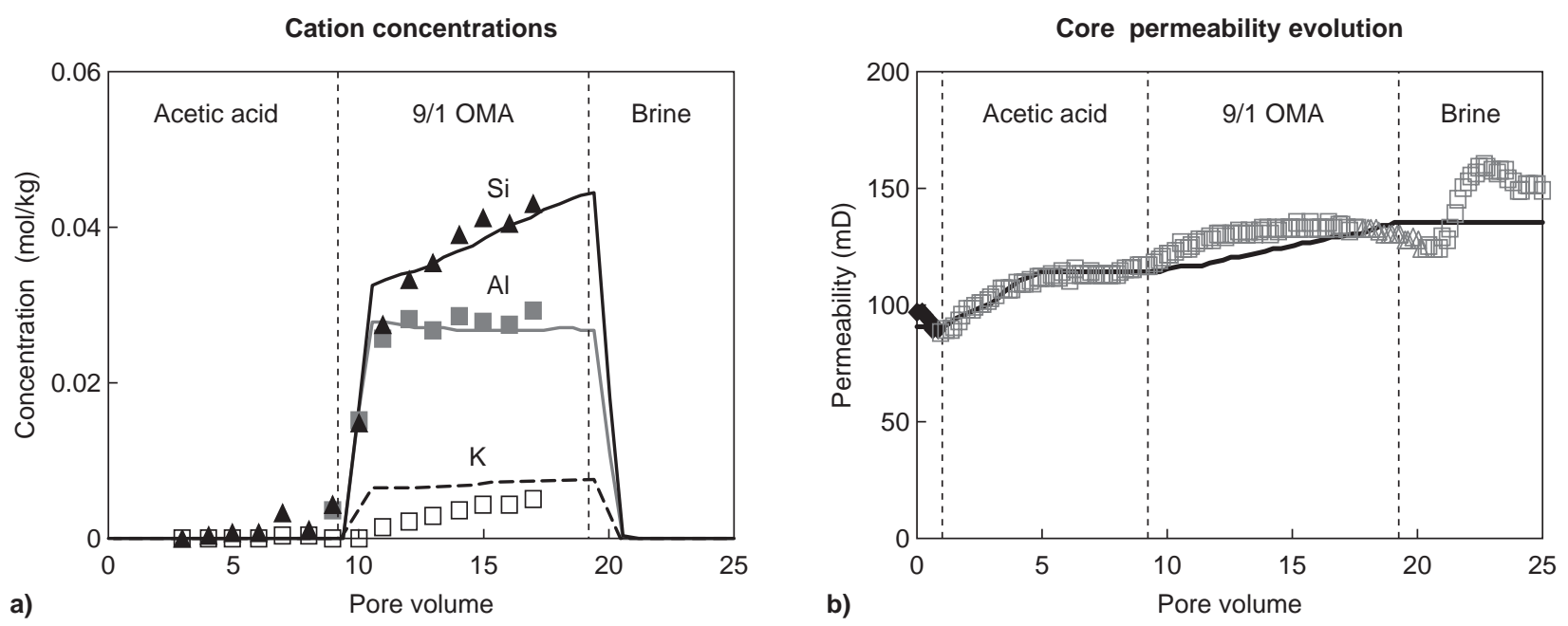

Figure 12

Case study 3. Cation concentrations and permeability from core flow test. 

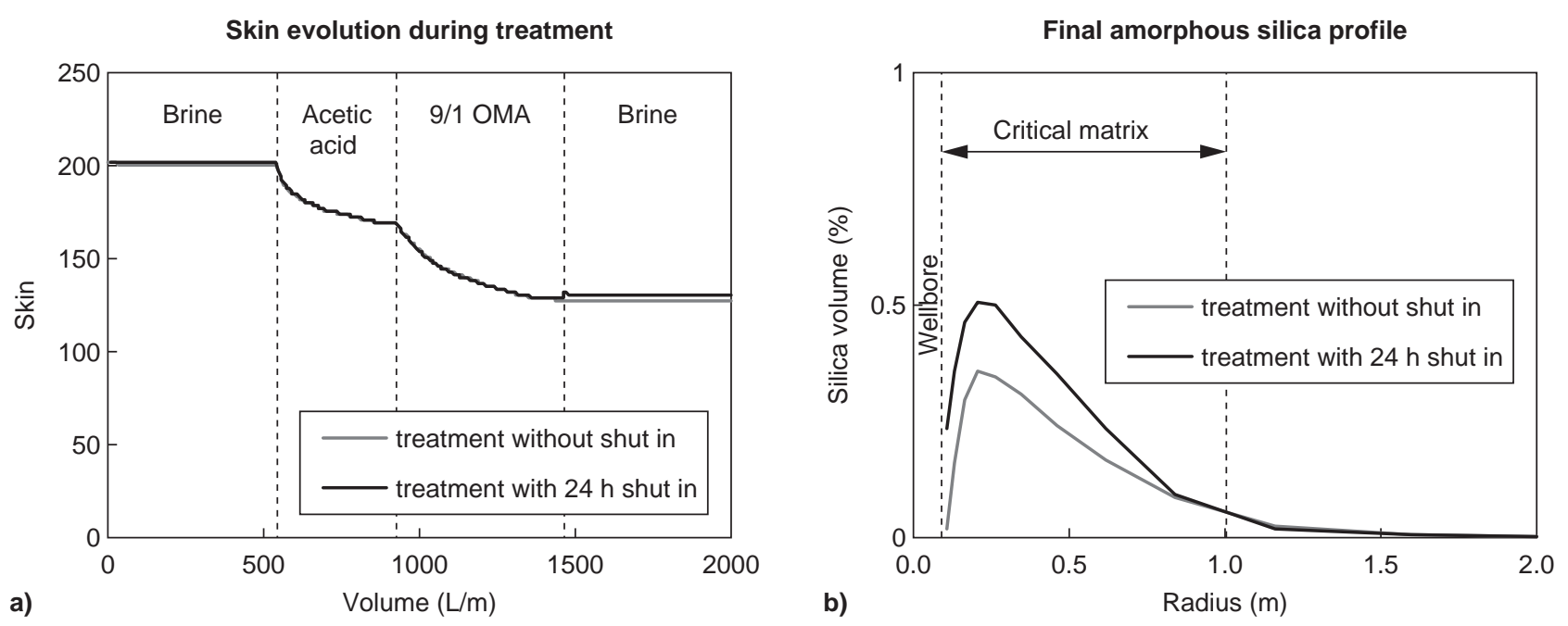

Figure 13

Case study 3. a) skin evolution during treatment, and b) effect of delay in flowback on amorphous silica precipitated in the formation.

permeability at the reservoir scale. The damage was assumed to be due only to fines migration in the simulation. Figure 13a shows that the computed skin declines steadily with injection of 9/1 OMA. Figure 13b shows the profile of amorphous silica precipitate after injection of 9/1 OMA, which is an indicator of the extent of primary and secondary reactions. The figure shows that the total volume of amorphous silica is small. These results show that the increase in permeability due to the dissolution of aluminosilicates is more dominant than the decrease in permeability due to precipitation of amorphous silica. Therefore, a steady decline skin is observed with continued injection of 9/1 OMA.

\subsubsection{Treatment Execution and Results}

The treatment was executed as planned except that it was not possible to flow back the well at the designed rates. Because of operational problems, the flowback took about $24 \mathrm{~h}$ instead of $2 \mathrm{~h}$ as initially planned. The additional residence time of fluids in the well caused further precipitation from secondary and tertiary reactions near the wellbore. The geochemical simulator was used again to estimate the quantity of amorphous silica precipitated because of this delay in flowback. Figure 13b shows that at the end of the flowback period, the total quantity of amorphous silica was still small, and therefore the delayed flowback was thought to have minimal impact on the final treatment.

The stimulation treatment increased the production from approximately 31.8 to $477 \mathrm{Sm}^{3} / \mathrm{d}$ immediately after the treatment. This represents an increase of more than $1400 \%$. Three weeks after the treatment, the production rate was about $397.5 \mathrm{Sm}^{3} / \mathrm{d}$. After 3 months the well was producing steadily at $238.5 \mathrm{Sm}^{3} / \mathrm{d}$. This represents an increase of $650 \%$ over the prestimulation rates.
The production increase was much larger than what is typically achieved after removal of fines migration damage. It is consistent with Figure 13a, which shows only a small improvement in skin after the treatment, when fines migration is the only damage mechanism. It is, therefore, possible that the dominant damage was due to $\mathrm{CaCO}_{3}$ scale or drilling and completion fluids losses and not to fines migration. A flowback analysis or post-treatment log was not available to test this hypothesis. $\mathrm{Ca}^{+2}$ presence in the flowback would have suggested $\mathrm{CaCO}_{3}$ either from scale or drilling fluids. A $\log$ after the treatment would have identified zones contributing to the additional production. If the zones producing with a high water cut had been contributing to additional production, then damage due to $\mathrm{CaCO}_{3}$ scale would have been more likely. However, if the zones that were originally producing dry oil or no fluids at all had been stimulated, then damage due to $\mathrm{CaCO}_{3}$ scale would have been less likely. Furthermore, because of equipment failure, it was not possible to determine during which stage in the treatment the greatest gain in injectivity was achieved.

If such data were available, the geochemical simulator could have been used to estimate the contributions of the various damage mechanisms.

\section{CONCLUSIONS}

This paper presents a new technique for quantifying the extent of secondary and tertiary reactions during sandstone acidizing treatments. The new technique uses only one or two short reservoir cores $(2.5$ to $15 \mathrm{~cm})$ to determine the type, quantity, and location of precipitates in the reservoir. Previous techniques required the use of long cores ( 0.3 to $0.9 \mathrm{~m}$ ) or elaborate radial flow setups for such determination. 
Long reservoir cores are difficult to obtain and the cost of radial flow experiments can be prohibitive. The use of short reservoir cores by the new technique makes it more accessible for routine treatment design.

In the new technique, tests on short cores are used to determine surface areas of minerals and the porositypermeability relationship for the formation. This information is then mathematically combined with previously archived reaction kinetics of secondary and tertiary reactions of the individual minerals to determine precipitation under reservoir treatment conditions.

The presented case studies show that successful matrix stimulation treatments can be designed for complex reservoirs using the new technique.

In the first case study, the technique was used to define the optimal volumes of preflush and clay stabilizing acids in the treatment. Because of the incompatibility of the clay stabilizing acid with carbonate, it was important to determine the radius around the wellbore where the preflush stage would effectively dissolve the carbonate. Also, the volume of clay stabilizing acid was calculated so that no contact occurred with the remaining carbonate, and that secondary and tertiary reactions did not damage the formation.

In the second case study, it was found that the damage caused by mud acid can be successfully removed by introducing a flowback stage soon after displacing the acid into the reservoir. The polymerization reactions of amorphous silica were slow enough at the reservoir temperature to allow its partial removal.

In the last case study, we show that the new technique was also helpful to demonstrate that the damage caused by secondary and tertiary reactions due to a delay in flowback was small. It was not possible to identify the dominant damage mechanism conclusively, as data for analysis were limited due to budget constraints and operational problems during the treatment. However, even with the limited data, the sensitivity analysis with the new technique did provide additional insight into likely damage mechanisms for the well. The treatment designed with the new technique resulted in a successful stimulation.

\section{ACKNOWLEDGEMENTS}

The authors thank Schlumberger for permission to publish this paper. The authors would also like to thank the following contributors for the case studies:

- Chevron Texaco and C. Torres, N. Suntonbura, J. Xiao, R. Tibbles, S. Aung Zaw Min, and S. Kumar for their help with the first case study.

- Statoil and their partners in the Heidrun license, and H. Kotlar, O. Vikane, H. Poitrenaud, M. Patey, L. Morris, and K. E. Wennberg for their contribution in the second case study.
- Chevron-Texaco and their partners ENI UK Ltd, and Summit UK Oil Ltd, in the Galley license, and M. Gillard, D. Healey, I. Archibald, J. Thomas, M. Taylor, L. Morris, and R. Warren for the final case study.

\section{REFERENCES}

1 Rae, P. and di Lullo, G. (2003) SPE 82260, Matrix Acid Stimulation-A Review of the State-of-the-Art. SPE European Formation Damage Conference, The Hague, The Netherlands.

2 Ziauddin, M., Berndt, O. and Robert, J. (1999) SPE 54728, An Improved Sandstone Acidizing Model: The Importance of Secondary and Tertiary Reactions. SPE European Formation Damage Conference, The Hague, The Netherlands.

3 Gdanski, R.D. (1997) SPE 37214, Kinetics of the Secondary Reaction of HF on Alumino-Silicates. SPE International Symposium on Oilfield Chemistry, Houston, TX.

4 Gdanski, R.D. (1996) SPE 31076, Kinetics of Tertiary Reaction of HF on Alumino-Silicates. International Symposium on Formation Damage Control, Lafayette, LA.

5 Van Everdingen, A.F. and Hurst, W. (1949) The Application of the Laplace Transformation to Flow Problems in Reservoirs. Trans., AIME 186, 305-324.

6 Fambrough, J.D. and Newhouse, D.P. (1993) A Comparison of Short-Core and Long-Core Acid Flow Testing for Matrix Acidizing Design. SPE Gas Technology Symposium No. 26186, Calgary, Canada.

7 Gdanski, R.D. (1995) Fractional Pore Volume Acidizing Flow Experiments. SPE European Formation Damage Conference No. 30100, The Hague, the Netherlands.

8 Wehunt, C.D. et al. (1993) Laboratory Acidization of an Eolian Sandstone at $380^{\circ} \mathrm{F}$. SPE International Symposium on Oilfied Chemistry No. 25211, New Orleans, LA.

9 Gdanski, R.D. (1985) $\mathrm{AlCl}_{3}$ Retards HF Acid for More Effective Stimulation. OGJ, 111-115.

10 Kotlar, H. and Hove, A. (2000) Acid Stimulation Studies in Simulated Radial Flow Conditions: Laboratory Results Compared with Field Data. SPE International Symposium on Formation Damage, Lafayette, LA.

11 Hartman, R.L., Lecerf, B, Ziauddin, M, Frenier and W, Fogler, H.S. (2003) Acid Sensitive Aluminosilicates: Dissolution Kinetics and Fluid Selection for Matrix Stimulation Treatments. SPE European Formation Damage Conference No. 82267, The Hague, The Netherlands.

12 Lund, K. and Fogler, H.S. (1976) Acidization-V: The Prediction of the Movement of Acid and Permeability Fronts in Sandstone. Chem. Eng. Sci. 31, 381-392.

13 Bryant, S.L. (1991) An Improved Model of Mud Acid/ Sandstone Chemistry. SPE Annual Technical Conference and Exhibition No. 22855, Dallas, TX.

14 da Motta, E.P., Plavnlk, B., Schechter, R.S. and Hill, A.D. (1993), Accounting for Silica Precipitation in the Design of Sandstone Acidizing. SPE Production and Facilities.

15 Li, Y., Fambrough, J.D., and Montgomery, C.T. (1998) Mathematical Modeling of Secondary Precipitation from Sandstone Acidizing. SPE International Symposium on Formation Damage Control No. 39420, Lafayette, LA.

16 Sevougian, S.D., Lake, L.W.and Schechter, R.S. (1995), KGEOFLOW: A New Reactive Transport Simulator for Sandstone Matrix Acidizing. SPE Production and Facilities, 13-19. 
17 Wagman, D., et al. (1982) The NBS Tables of Chemical Thermodynamic Properties. Selected Values for Inorganic and $\mathrm{C} 1$ and C2 Organic Substances in SI Units Supplement, J. Phys and Chem. Ref. Data, 11, 2, 2-392.

18 Shock, E.L. and Helgeson, H.C. (1988) Calculation of the Thermodynamic and Transport Properties of Aqueous Species at High Pressures and Temperatures: Correlation Algorithms for Ionic Species and Equation of State Predictions to $5 \mathrm{~kb}$ and $1000^{\circ} \mathrm{C}$. Geochim. Cosmochim. Acta, 52, 2009-2036.

19 Linke, F. (1965) Solubilities of Inorganic and Metal-Organic Compounds, fourth ed.,2, Washington, D.C. American Chemical Society.

20 Labrid, J.C. (1975) Thermodynamic and Kinetic Aspects of Argillaceous Sandstone Acidizing. SPE Journal, 117.

21 Hsi, C.D., Bryant S.L. and Neira R.D (1993) Experimental Validation of Sandstone Acidization Models, SPE International Symposium on Oilfield Chemistry No. 25212, New Orleans, LA.

22 Ziauddin, M., Kotlar, H. K, Vikane, O., Frenier, W. and Poitrenaud, H. (2002) The Use of a Virtual Chemistry Laboratory for the Design of Matrix Stimulation Treatments in the Heidrun Field. SPE European Petroleum Conference No. 78314, Aberdeen, Scotland.
23 Torres, C., Ziauddin, M., Suntonbura, N., Xiao, J. and Tibbles, R. (2003) Application of a Unique Clay Stabilizing Acid in the Gulf of Thailand. PetroMin Deepwater Technology, Kuala Lumpur, Malaysia.

24 Ziauddin, M., Gillard, M., Lecerf, B., Frenier, W., Archibald, I. and Healey, D. (2004) Method for Characterizing Secondary and Tertiary Reactions Using Short Reservoir Cores. SPE International Symposium on Formation Damage No. 86520, Lafayette, LA.

25 Thomas, R.L. and Crowe, C.W. (1978) Matrix Treatment Employs New Acid System for Stimulation and Control of Fines Migration in Sandstone Formations. SPE Annual Fall Meeting No. 7566, Houston, TX.

2 McBride, J.R., Rathbone, M.J., Thomas, R.L. (1979) Evaluation of Fluoboric Acid Treatment In The Grand Isle Offshore Area Using Multiple Rate Flow Test, 54th Annual Fall Technical Conference and Exhibition of the Society of Petroleum Engineers of AIME No. 8399. Las Vegas.

27 Thomas, R.L. and Crowe, C.W. (1981) Matrix Treatment Employs New Acid System for Stimulation and Control of Fines Migration in Sandstone Formations, Journal of Petroleum Technology, 1491-1500.

Final manuscript received in November 2004 